\title{
Infection Efficiency of Magnaporthe grisea Isolates Causing Blast in Rice and Pearl Millet
}

\author{
Mukesh Kumar ${ }^{1 *}$, Pramod Kumar Moury ${ }^{2}$, P. Sinha ${ }^{1}$, K. Vishwanath ${ }^{1}$ and P. Sharma ${ }^{1}$ \\ ${ }^{1}$ Division of Plant Pathology, ${ }^{2}$ Discipline of Agricultural Statistics, ICAR-IASRI, \\ New Delhi-110012, India \\ *Corresponding author
}

\section{A B S T R A C T}

\begin{tabular}{|l|}
\hline K e y w o r d s \\
$\begin{array}{l}\text { Infection efficiency, } \\
\text { Incubation period, M. } \\
\text { grisea, rice, Pearl millet, } \\
\text { leaf blast, Isolate, } \\
\text { Appressorium }\end{array}$ \\
\hline Article Info \\
\hline $\begin{array}{l}\text { Accepted: } \\
\text { 15 September } 2018 \\
\text { Available Online: } \\
\text { 10 October } 2018\end{array}$ \\
\hline
\end{tabular}

\section{Introduction}

Infection efficiency as a measure of pathogen growth or symptom development is an important parameter to testify host specificity as well as resistance against any pathogen.

For fungal conidial germination, germ tube growth, appressorium formation, penetration as well as subsequent growth and sporulation are influenced by host specificity.

Leaf blast pathogen Magnaporthe grisea has been reported to be causal agent in rice, pearl millet as well as 50 other grasses (Mehta et al., 1953; Ou, 1985; Ou, 1987; Timper et al.,
2002; Cardoso et al., 2008). But several studies reported that isolates from grasses differ from isolates infecting rice (Hemmi et al., 1949; Suzuki and Hashomoto, 1953; Zellerholf et al., 2006; Choi et al., 2013).

However, contradictory reports from cross inoculation studies indicated that the question of isolate specificity is still unresolved.

Present report deals with the infection efficiency in terms of incubation period and cross infectivity of isolates in terms of appressorium formation on pearl millet and rice leaves causing blast in both the crops. 


\section{Materials and Methods}

\section{Collection of infected leaf samples and} isolation

A virulent isolate, $\mathrm{Mj}$ of leaf blast on rice was obtained from the cereal pathology laboratory, Division of Plant Pathology IARI, New Delhi, whereas pearl millet isolate was isolated from the blast infected leaf samples from affected pearl millet crop of the IARI Experimental filed. Pearl millet isolate was purified by hyphal-tip method (Dhingra and Sinclair, 1995). Both the isolates were maintained on PDA slants and stored at $4^{\circ} \mathrm{C}$.

\section{Preparation of spore suspension and inoculation}

The cultures were incubated in $326 \mathrm{~nm}$ Near UV light at $28^{\circ} \mathrm{C}$ for five to six days. Spore suspension was prepared scrapping the slant surface with aseptic needle and spore count (based on haemocytometer count) was adjusted to a concentration of $1 \times 10^{5}$ per $\mathrm{ml}$ with sterile distilled water. For isolation of $M$. grisea isolate from pearl millet, infected tissue was incubated on rice extract sucrose agar incubated at $28^{\circ} \mathrm{C}$ with exposure to Near UV light $(326 \mathrm{~nm})$ for overnight.

\section{Raising rice and pearl millet plant}

Plastic pots (5 $\mathrm{cm}$ diameter) were filled with autoclaved soil-sand-FYM mix $(2: 1: 1$ by volume). Seeds of rice (Pusa basmati 1) and pearl millet (male restorer line) were sown in pots (10 seeds/ pot) in a glasshouse maintained at $32^{\circ} \mathrm{C}$, with regular irrigation of the pots seedlings were grown for 25 days.

\section{Determination of incubation period in rice and pearl millet}

After inoculation, inoculated plants were observed daily for lesion count till 10 days.
From inoculation to development of $50 \%$ of the lesion has been considered as incubation period $\left(\mathrm{IP}_{50}\right)$ for blast. Number of lesion was converted to cumulative frequency percentage and plotted against days and the time required for development of $50 \%$ of the spots was estimated from the graph as $\mathrm{IP}_{50}$.

Infection efficiency of isolates on rice and pearl millet

Infection efficiency as a measure of pathogen growth or lesion development has been estimated as reciprocal of incubation period.

\section{Cross-inoculation of detached leaf in moist petriplates and incubation}

Sterilized petriplates $(14 \mathrm{~cm})$ were used to make moist chamber using autoclaved filter papers that were moistened with sterile water. Sterilized glass slides were used to stick detached leaves on glass slide with adhesive labels. Forty-five days old leaves both from rice and pearl millet was fixed on sticky slides and $45 \mu 1$ of spore suspension of each isolate was applied on both types of leaf surfaces. The plates were then incubated at dark for 24 hrs $25-26^{\circ} \mathrm{C}$ and then transferred to $12 \mathrm{~h}$ day light and dark night.

\section{Observation}

Inoculated seedlings of both rice and pearl millet were observed everyday visually for spot appearance.

\section{Results and Discussion}

Incubation period of pearl millet isolate on pearl millet and rice isolate on rice

Blast lesion was observed after 24 hour of inoculation. Based on the number of blast lesions developed up to 10 days after inoculation, incubation period $\left(\mathrm{IP}_{50}\right)$ in pearl 
millet was estimated to be about 4.98 days (Table 1 and Figure 1). In rice $\mathrm{IP}_{50}$ was estimated to be about 6.23 days (Table 2 and Figure 2).

\section{Infection efficiency in pearl millet and rice}

Infection was estimated as reciprocal of $\mathrm{IP}_{50}$. In pearl millet infection efficiency was 0.2040 and in rice it was 0.1605 (Table 3). It indicated that infection efficiency on pearl millet was comparatively higher than on rice (Fig. 3).

Cross infectivity of pearl millet and rice isolates on pearl millet and rice

Conidia of rice isolate of $P$. oryzae were found to germinate and form appressoria on pearl millet leaf surface more easily than on rice surface (Plate 1, Table 4). Similarly, conidia of pearl millet isolate of $P$. grisea were also found to germinate and form appressoria on pearl millet leaf surface more easily than on rice surface (Plate 2).

Scanning micrograph of pearl millet and rice leaf surface

Leaf surface features indicated wide differences so for as number of parallel viens, trichomes, grooves and wedges visible on the surface (Plate 3 and 4). In pearl millet fewer numbers of parallel veins and trichomes were seen as compare to rice leaf. In pearl millet surface view was characterized by the presence of groove like depression but in rice in absence of grooves in numerous number of wedges was observed. These morphological structural differences in leaf surfaces are responsible for surface hydrophobicity differences and wettability of leaf surface which in turn decides the appressoria formation.

Table.1 Incubation period (IP50) on pearl millet from inoculation to blast symptom expression

\begin{tabular}{|l|c|c|c|}
\hline Days & No. of spots (average) & Cumulative frequency & Cumulative frequency \% \\
\hline $\mathbf{1}$ & 0 & 0 & 0 \\
\hline $\mathbf{2}$ & 0.4 & 0.4 & 3.07 \\
\hline $\mathbf{3}$ & 0.8 & 1.2 & 9.23 \\
\hline $\mathbf{4}$ & 2.4 & 3.6 & 27.69 \\
\hline $\mathbf{5}$ & 3.1 & 6.7 & 51.53 \\
\hline $\mathbf{6}$ & 3.1 & 9.8 & 75.38 \\
\hline $\mathbf{7}$ & 3.2 & 13 & 100 \\
\hline
\end{tabular}

Table.2 Incubation period (IP50) on rice from inoculation to blast symptom expression

\begin{tabular}{|l|c|c|c|}
\hline Days & No. of spots (average) & Cumulative frequency & Cumulative frequency \% \\
\hline $\mathbf{1}$ & 0 & 0 & 0 \\
\hline $\mathbf{2}$ & 0.3 & 0.3 & 2.77 \\
\hline $\mathbf{3}$ & 0.7 & 1 & 9.25 \\
\hline $\mathbf{4}$ & 1.2 & 2.2 & 20.37 \\
\hline $\mathbf{5}$ & 1.4 & 3.6 & 33.33 \\
\hline $\mathbf{6}$ & 1.6 & 5.2 & 48.14 \\
\hline $\mathbf{7}$ & 2.8 & 8 & 74.07 \\
\hline $\mathbf{8}$ & 2.6 & 10.6 & 100 \\
\hline
\end{tabular}


Table.3 Infection efficiency of rice and pearl millet blast

\begin{tabular}{|l|l|}
\hline Host & Infection efficiency \\
\hline Rice & 0.142857 \\
\hline Pearl millet & 0.208333
\end{tabular}

Table.4 Appressorium formation assay on pearl millet and rice leaf surface

\begin{tabular}{|l|c|c|c|c|}
\hline $\begin{array}{l}\text { Serial } \\
\text { no. }\end{array}$ & $\begin{array}{c}\text { No. of millet surface } \\
\text { conidia }\end{array}$ & $\begin{array}{c}\text { Appressoria } \\
\text { formed }\end{array}$ & $\begin{array}{c}\text { Ro. of } \\
\text { conidia }\end{array}$ & $\begin{array}{c}\text { Appressoria } \\
\text { formed }\end{array}$ \\
\hline $\mathbf{1}$ & 38 & 18 & 22 & 3 \\
\hline 2 & 36 & 14 & 18 & 2 \\
\hline 3 & 38 & 16 & 18 & 3 \\
\hline 4 & 42 & 17 & 20 & 5 \\
\hline 5 & 49 & 21 & 21 & 4 \\
\hline 6 & 45 & 17 & 25 & 4 \\
\hline 7 & 46 & 20 & 23 & 3 \\
\hline 8 & 43 & 21 & 25 & 1 \\
\hline 9 & 40 & 16 & 17 & 2 \\
\hline 10 & 36 & 18 & 16 & 3 \\
\hline Avera & 41.3 & 17.8 & 20.5 & 3 \\
\hline ge & & & & \\
\hline
\end{tabular}

Fig.1 Incubation period (IP50) on pearl millet from inoculation to blast symptom expression

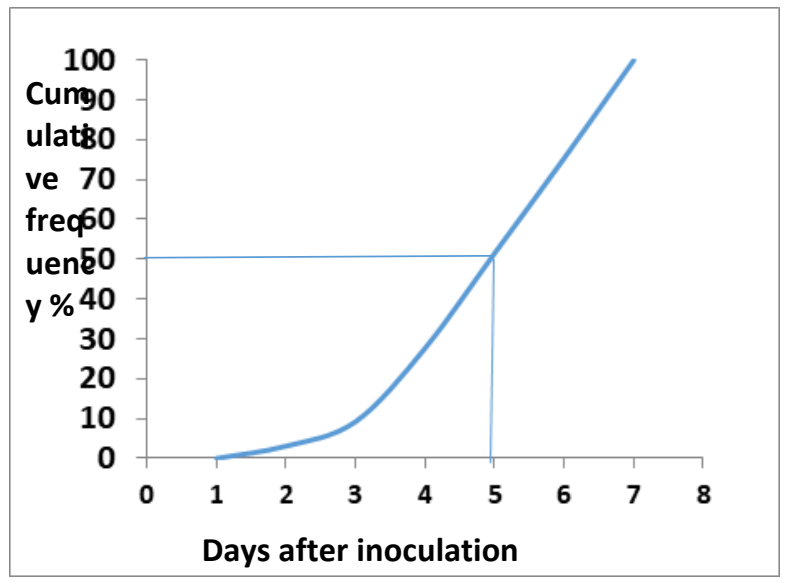


Fig.2 Incubation period (IP50) on rice from inoculation to blast symptom expression

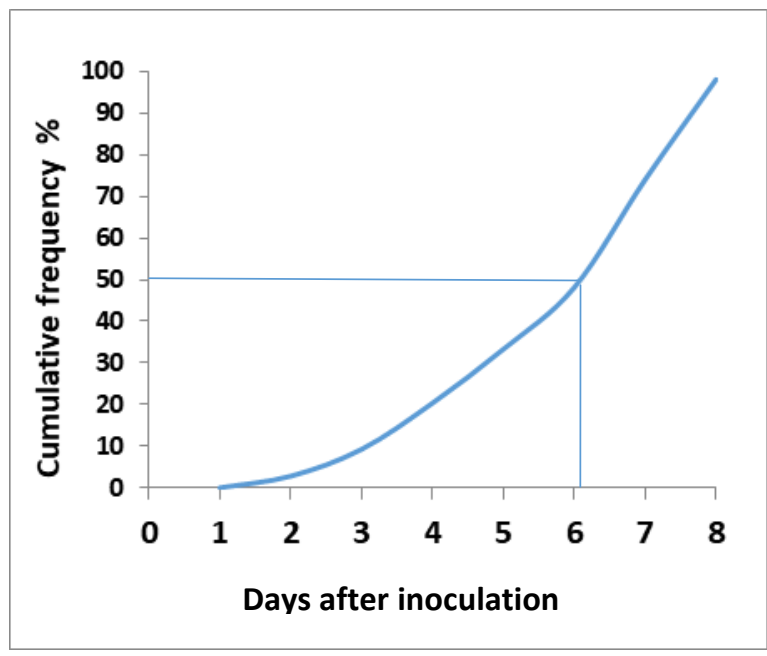

Fig.3 Infection efficiency of rice and pearl millet blast isolates on their host

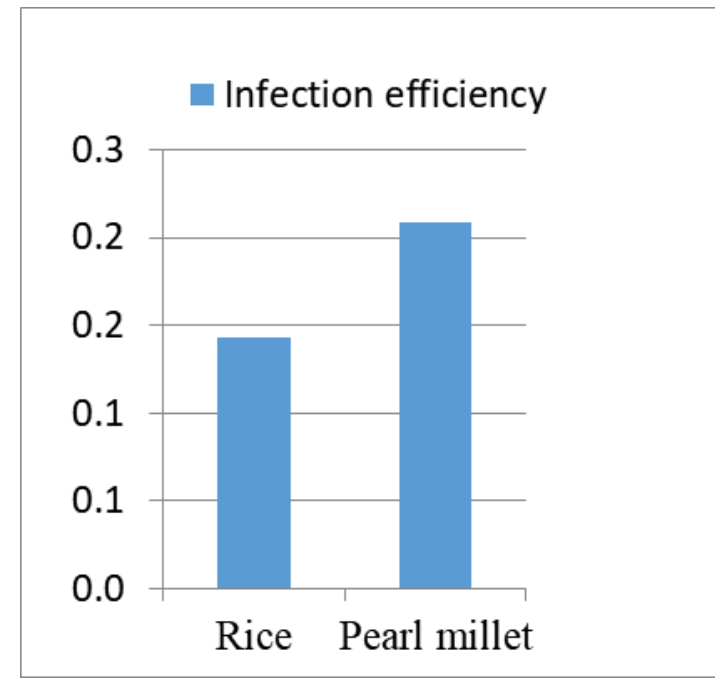

\section{Infection efficiency $=1 /$ IP}

Plate.1 Rice isolate on pearl millet leaf surface. A. Conidia germination appressoria formation differentiation and localisation near to stromata leaving three cells B. and C. Penetration peg formation at cell joints, D. Direct penetration

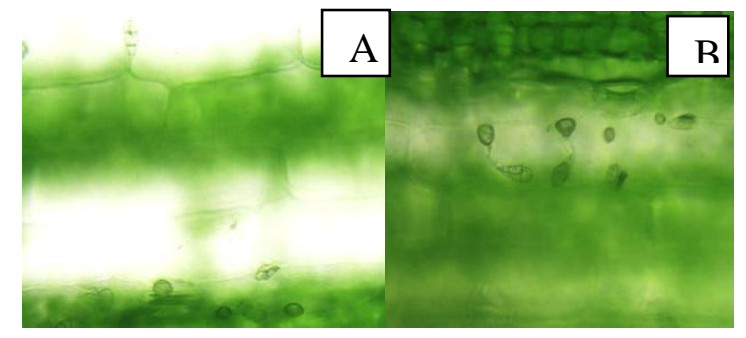




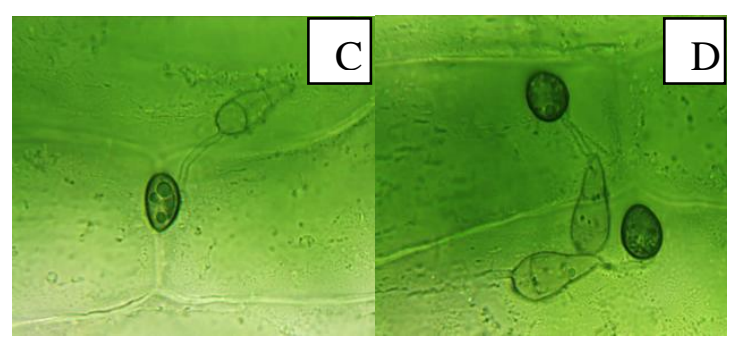

Plate.2 Pearl millet isolate on pearl millet leaf surface. A and B. Conidia germination, appressoria formation and surface penetration at cell joints, C. Conidia regeneration on leaf surface, D. Typical symptom expression
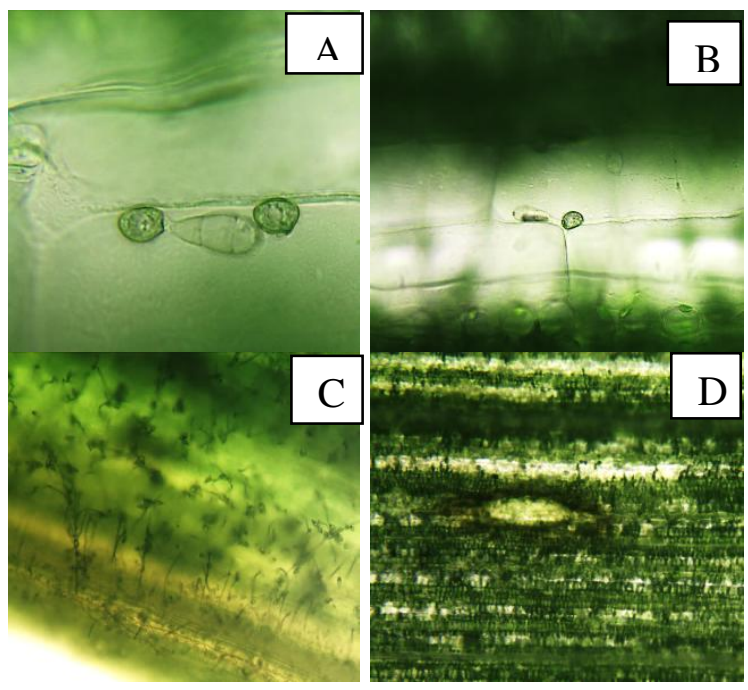

Plate.3 SEM of pearl millet leaf surface at A. 608X and B. 1.29 KX magnification

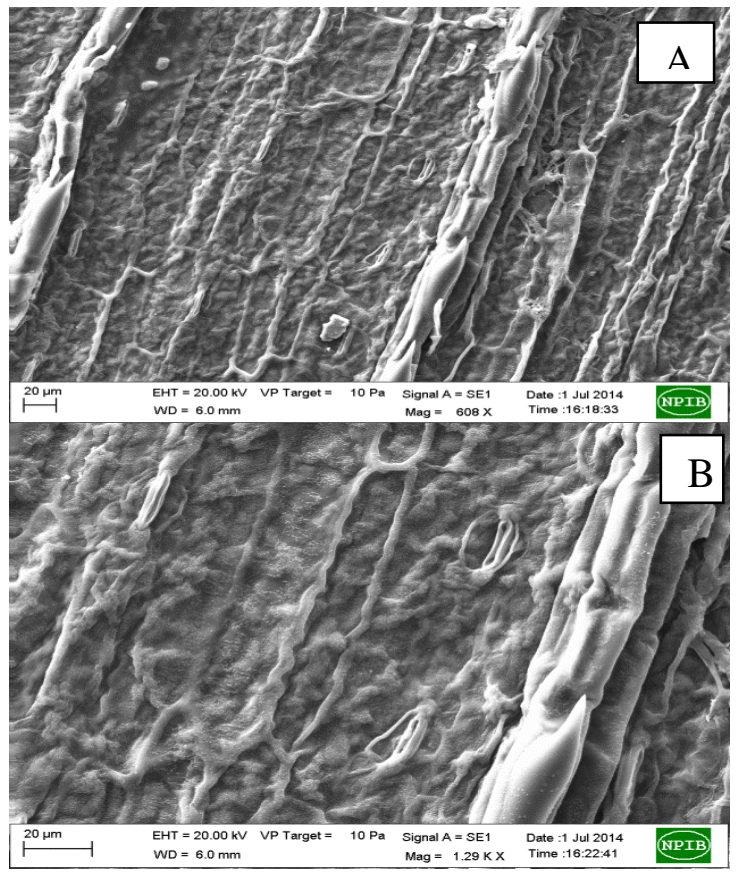


Plate.4 SEM of rice leaf surface at A. 608X and B. 1.29 KX magnification

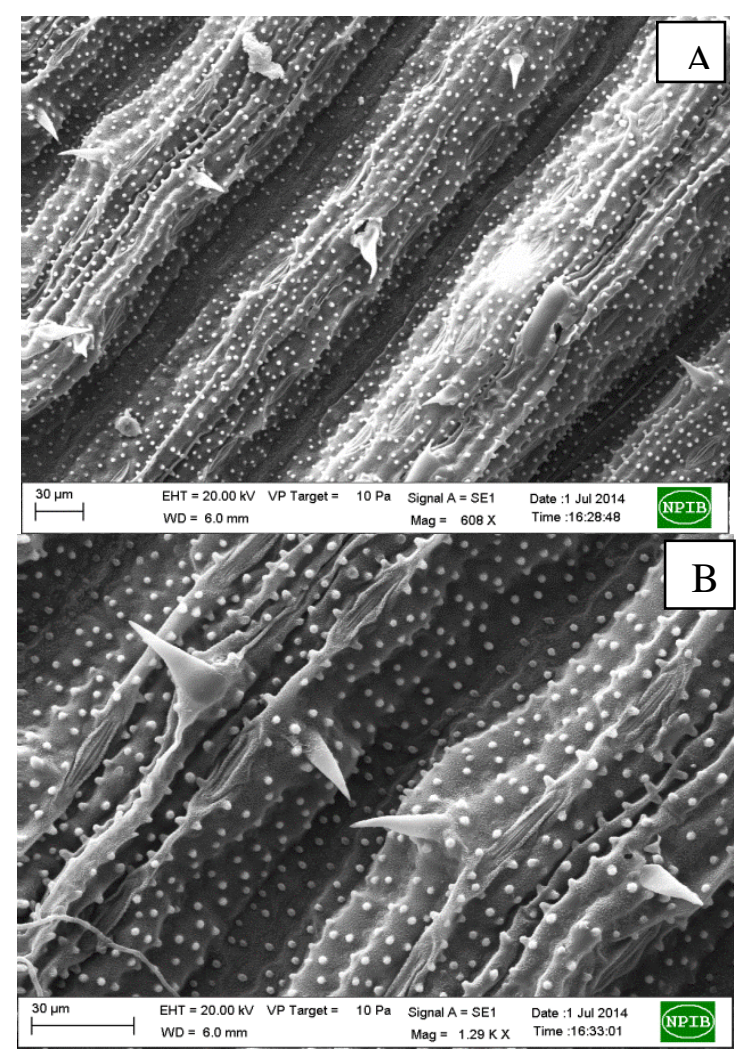

Infection efficiency a measure of pathogen growth or symptom development is an important parameter to testify host preference. $M$. grisea has been reported to be the pathogen to cause leaf blast in rice (Cavara, 1892), pearl millet (Mehta et al., 1953) and wheat (Cardoso et al., 2008). Although leaf blast in rice has drawn attention widely but the pathogen has been first isolated from crabgrass (Saccardo, 1880).

To testify host preference, incubation period as measure of infection efficiency for isolates of leaf blast pathogen in pearl millet and rice has been estimated. Incubation period $\left(\mathrm{IP}_{50}\right)$ for leaf blast symptom development on pearl millet and rice using respective isolate (pearl millet isolate on pearl millet and rice isolate on rice) were estimated to be 4.98 and 6.23 days respectively at $26^{\circ} \pm 1^{\circ} \mathrm{C}$. Infection efficiency estimated from the $\mathrm{IP}_{50}$ is 0.2040 and 0.1605 in respect of pearl millet and rice.
It indicates that pearl millet is the better host for the pathogen if they are the same pathogen.

However, cross infectivity of rice and pearl millet isolate on pearl millet had shown significantly higher of number of appressorium to conidia than in rice host where conidia germination and appressorium formation looked to be scanty under similar incubation conditions.

Therefore, it appeared that that for blast infection germination, germ tube growth, appressoria formation are influenced by host surface difference. It became evident there is lot of difference in surface characteristics observed through scanning micrography. Therefore, surface differences in the structure of leaves along with adhesion, retention and distribution of water sprays or rainfall drops on plant surfaces. 


\section{Acknowledgement}

Authors are thankful to the PG school, Division of Plant Pathology and Division of Entomology, Indian Agricultural Research Institute New Delhi for providing the necessary facilities in accomplishing the research work.

\section{References}

Cardoso, C. A. D. A., Reis, E. M. and Moreira, E. N. (2008). Development of a warning system for wheat blast caused by Pyricularia grisea. Summa Phytopathologica. 34(3): 216-221.

Cavara, F. (1892). Fungi Longobardiae exsiccati. Pugillus II. Pavia.

Choi, J., Park, S. Y., Kim, B. R., Roh, J. H., Oh, I. S., Han, S. S. and Lee, Y. H. (2013). Comparative analysis of pathogenicity and phylogenetic relationship in Magnaporthe grisea species complex. PloS one. 8: e57196.

Dhingra, O. D., and Sinclair, J. B. (1995). Basic Methods in plant pathology. $C R C$, Boca Raton.

Hemmi, T., Yamamoto, M., Yamakura, K. and Kusakabe, T. (1949). Studies on the blast fungus of Indian corn. Ann. Phytopathol. Soc., Japan. 13: 23-25.
Mehta, P. R., Singh, B. and Mathur, S. C. (1953). A new leaf spot disease of Bajra (Pennisetum typhoides Stapf and Hubbard) caused by a species of Pyricularia. Indian Phytopathology. 5(2): 140-143.

Ou, S. H. (1985). Rice diseases, $2^{\text {nd }}$ Edition. Common Wealth Mycological Institute, Kew, Surrey, England. p. 379.

Ou, S. H. (1987). Rice diseases. Surrey: The Commonwealth Mycological Institute. pp. 109-201.

Suzuki, H., Hashimoto, Y. (1953). Pathogenicity of the rice blast fungus to plants other than rice. Ann. Phytopathol. Soc., Japan. 17: 94-95.

Timper, P., Wilson, J. P., Johnson, A. W., and Hanna, W. W. (2002). Evaluation of pearl millet grain hybrids for resistance to Meloidogyne spp. and leaf blight caused by Pyricularia grisea. Plant disease. 86(8): 909-914.

Zellerhoff, N., Jarosch, B., Groenewald, J. Z., Crous, P. W. and Schaffrath, U. (2006). Non host resistance of barley is successfully manifested against Magnaporthe grisea and a closely related Pennisetum-infecting lineage but is overcome by Magnaporthe oryzae. Molecular plant-microbe interactions. 19(9): 1014-1022.

\section{How to cite this article:}

Mukesh Kumar, Pramod Kumar Moury, P. Sinha, K. Vishwanath and Sharma, P. 2018. Infection Efficiency of Magnaporthe grisea Isolates Causing Blast in Rice and Pearl Millet. Int.J.Curr.Microbiol.App.Sci. 7(10): 1865-1872. doi: https://doi.org/10.20546/ijcmas.2018.710.214 